\title{
Ionic Liquid-Based Ultrasound-Assisted Emulsification Microextraction Coupled with HPLC for Simultaneous Determination of Glucocorticoids and Sex Hormones in Cosmetics
}

\author{
Xiaoji Cao", Lingxiao Shen, Xuemin Ye, Feifei Zhang, Jiaoyu Chen, Weimin Mo* \\ Research Center of Analysis and Measurement, Zhejiang University of Technology, Hangzhou, China \\ Email: *xiaojicao@zjut.edu.cn, *mowm@zjut.edu.cn
}

Received March 20, 2013; revised April 21, 2013; accepted April 28, 2013

Copyright (C) 2013 Xiaoji Cao et al. This is an open access article distributed under the Creative Commons Attribution License, which permits unrestricted use, distribution, and reproduction in any medium, provided the original work is properly cited.

\begin{abstract}
An effective and environmentally friendly method based on ionic liquid-based ultrasound-assisted emulsification microextraction (IL-USAEME) and high performance liquid chromatography (HPLC) has been developed for the determination of nine hormones including three glucocorticoids, one androgen and five progestogens in cosmetics. Several factors that affect the extraction efficiency, such as the kinds and volume of ionic liquid, salt concentration, ultrasonic power and time, and centrifugation time were investigated and optimized. Under the optimum extraction condition, the recoveries of analytes ranged from $85.97 \%$ to $108.84 \%$ except prednisolone $(62.30 \%)$. The intraday and interday precision was below $2.51 \%$ and $3.30 \%$, respectively.
\end{abstract}

Keywords: Ionic Liquid; Ultrasound-Assisted Emulsification Microextraction; Hormones; Cosmetics; High Performance Liquid Chromatography

\section{Introduction}

Cosmetics have become more and more important in our daily life for skin whitening, anti-wrinkle, removing freckle, moisture, and so on [1]. In order to achieve these effects remarkably, illicit chemicals such as hormones are added to the cosmetics. And the potential accumulation hazard of these additives is terrible [2]. Although the Hygienic Standard for Cosmetic of China and European Union Directive 76/768/EEC has banned the addition of hormones to commercial cosmetics, cosmetics containing hormones are still in the market.

At present, the high performance liquid chromatography and its combination with mass spectrometry are the most common methods for determination of trace hormones in the complex matrices. For these analytic techniques, in order to decrease the interference of matrix and concentrate the targeted compounds, a sample pretreatment is indispensable, which is often laborious and consumes a large amount of organic solvents [3-5].

Ionic liquids (ILs) composed of organic cations and various types of anions have been successfully applied to

\footnotetext{
*Corresponding author.
}

various areas of analytical chemistry as environmental benign solvents [6-10]. Ionic liquid-based ultrasound- assisted emulsification microextraction (IL-USAEME) is an efficient, simple, rapid and cheap extraction technique, in which applying ultrasound radiation to facilitate the emulsification of a microvolume of ionic liquid extractant in an aqueous sample, and subsequent separation of the two immiscible liquid phases by centrifugation [11, 12]. This method has been used for the extraction of organic compounds in environmental samples. However, to the best of our knowledge, IL-USAEME has not been applied for the extraction of hormones from cosmetics.

In this paper, an ionic liquid-based ultrasound-assisted emulsification microextraction (IL-USAEME) combined with HPLC method for simultaneous determination of glucocorticoids and sex hormones in cosmetics will be investigated.

\section{Materials and Methods}

\subsection{Reagents and Chemicals}

The pharmaceutical standards (purity, $97.5 \%$ - 99.5\%) of androstendione, hydroxyprogesterone acetate, megestrol 
acetate and melengestrol acetate were purchased from Dr. Ehrenstorfer GmbH (Augsburg Germany). Northindrone was purchased from Toronto Research Chemicals Inc. (North York, Canada). Prednisolone and Beclometasone Dipropionate were purchased from the National Institutes for Food and Drug Control (NIFDC) (Beijing, China). Dexamethasone was purchased from Zhejiang Xianju Pharmaceutical Co., Ltd. (Zhejiang, China) and 17 ahydroxyprogesterone caproate was purchased from Tokyo Chemical Industry Co., Ltd. (Tokyo, Japan). Chromatographic grade methanol and acetonitrile were supplied by Merck (Darmstadt, Germany). Deionized water was purified by a Milli-Q water purification system (18 $\mathrm{M} \Omega$, Millipore, Bedford, MA, USA). [ $\left.\mathrm{C}_{6} \mathrm{MIM}\right]\left[\mathrm{PF}_{6}\right]$ and $\left[\mathrm{C}_{7} \mathrm{MIM}\right]\left[\mathrm{PF}_{6}\right]$ were gained from Chengjie Co. Ltd. (Shanghai, China) and used as received. The cosmetic products Kose were purchased from local supermarket and stored at room temperature.

\subsection{Ionic Liquid-Based Ultrasound-Assisted Emulsification Microextraction}

Ionic liquid-based ultrasound-assisted emulsification microextraction was performed in KQ-100 DA and KQ-500 DA ultrasonic water baths (Kunshan, Jiangsu, China). A $0.2 \mathrm{~g}$ cosmetic sample, $125 \mu \mathrm{l}\left[\mathrm{C}_{7} \mathrm{MIM}\right]\left[\mathrm{PF}_{6}\right], 62.5 \mu \mathrm{l}$ saturated $\mathrm{NaCl}$ aqueous solution and $187.5 \mu \mathrm{l}$ water were introduced to a $1.5 \mathrm{ml}$ eppendorf centrifuge tube. And the mixed solution was ultrasonically extracted at ultrasonic power of $100 \mathrm{~W}$ for $15 \mathrm{~min}$. The emulsification solution obtained after ultrasonication was centrifuged at 10000 rpm for $12 \mathrm{~min}$ by the Centrifuge 5804 (Eppendorf AG, Hamburg, Germany). After centrifugation, the IL extraction solution $(\sim 100 \mu \mathrm{l})$ which was deposited at the bottom of the centrifuge tube was collected using a $200 \mu \mathrm{l}$ pipette and then diluted by methanol to $1 \mathrm{ml}$. Finally, the solution was filtered through $0.22 \mu \mathrm{m}$ nylon filter membrance.

\subsection{HPLC Analyses}

The HPLC analysis was performed using a Waters 2695 HPLC system (Waters, Milford, MA, USA) equipped with a quaternary solvent delivery system, an auto-sampler with a $100 \mu \mathrm{l}$ sample loop, a PDA detector, a column oven, and a data station running the Empower data software. A CAPCELL PAK C18 column $(150 \mathrm{~mm} \times 4.6$ $\mathrm{mm}, 3 \mu \mathrm{m}$, Chuo-ku, Tokyo, Japan) was used for separation and was maintained at $25^{\circ} \mathrm{C}$. The mobile phase was composed of water (eluent A) and acetonitrile (eluent B), and the elution was carried out in gradient mode at a flow rate of $0.7 \mathrm{ml} / \mathrm{min}$. The gradient program was as follows: $0 \min -2 \min , 30 \% \mathrm{~B} ; 2 \min -6 \min , 30 \%-70 \% \mathrm{~B} ; 6$ $\min -15 \min , 70 \% \mathrm{~B} ; 15 \mathrm{~min}-16 \mathrm{~min}, 70 \%-100 \% \mathrm{~B}$; $16 \mathrm{~min}-25 \mathrm{~min}, 100 \%$ B. Finally, the initial condition was re-introduced over $0.01 \mathrm{~min}$, and the equilibration time was $5 \mathrm{~min}$. The injection volume was $10 \mu \mathrm{l}$. The detection wavelength was $242 \mathrm{~nm}$ for all the analytes except megestrol acetate and melengestrol acetate (288 $\mathrm{nm})$.

\section{Results and Discussion}

\subsection{Optimization of Extraction Conditions}

To acquire the high recoveries and enrichment efficiency of the studied hormones (shown as Figure 1), the effects of several factors, such as kinds of ionic liquid, volume of $\left[\mathrm{C}_{7} \mathrm{MIM}\right]\left[\mathrm{PF}_{6}\right]$, salt concentration, ultrasonic power and time, and centrifugation time, were examined and optimized.

\subsubsection{Screening of the IL-Based Extraction Solvent}

In the case of USAEME, the suitable extraction solvent should have density greater than that of water and also a low solubility in water [14]. And the structures of ILs have a significant effect on its physicochemical proper-
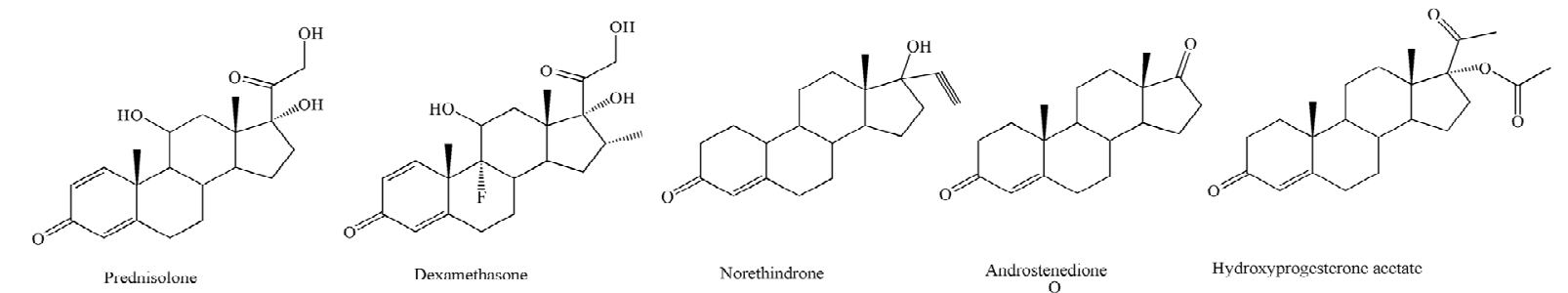

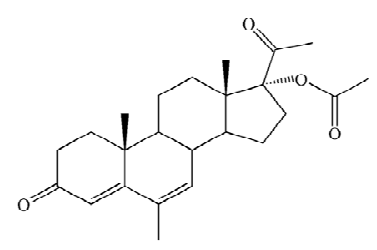

Megestrol acetate

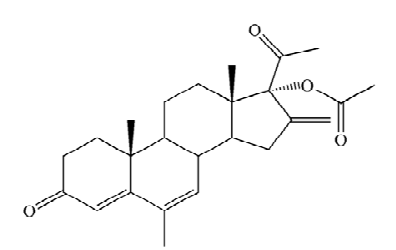

Melenuestrol acetate

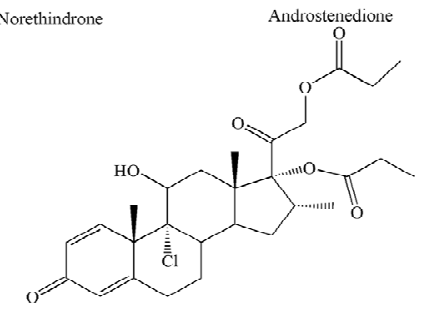

Beclumelasune diprupioniate

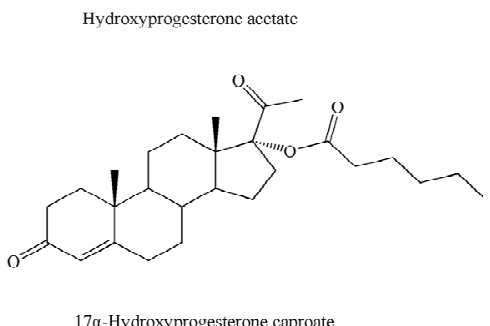

Figure 1. The chemical structures of the studied hormones. 
ties, which might greatly affect the extraction efficiency of targeted compounds [15]. In this study, two types of $\mathrm{IL}$, including $\left[\mathrm{C}_{6} \mathrm{MIM}\right]\left[\mathrm{PF}_{6}\right]$ and $\left[\mathrm{C}_{7} \mathrm{MIM}\right]\left[\mathrm{PF}_{6}\right]$ which are hydrophobic were examined. As shown in Figure 2, the $\left[\mathrm{C}_{7} \mathrm{MIM}\right]\left[\mathrm{PF}_{6}\right]$ extraction phase produced the better extraction performance for all hormones than that of the $\left[\mathrm{C}_{6} \mathrm{MIM}\right]\left[\mathrm{PF}_{6}\right]$, attributed to the stronger hydrophobic interactions between the longer alkyl chain of the $\left[\mathrm{C}_{7} \mathrm{MIM}\right]\left[\mathrm{PF}_{6}\right]$ ionic liquid and the hydrophobic hormones. Thus, $\left[\mathrm{C}_{7} \mathrm{MIM}\right]\left[\mathrm{PF}_{6}\right]$ was selected for all of the subsequent experiments.

\subsubsection{Effect of the Volume of $\left[\mathrm{C}_{7} \mathrm{MIM}\right]\left[\mathrm{PF}_{6}\right]$}

To study the influence of the volume of $\left[\mathrm{C}_{7} \mathrm{MIM}\right]\left[\mathrm{PF}_{6}\right]$ on the extraction efficiency, experiments were carried out by using different volumes of $\left[\mathrm{C}_{7} \mathrm{MIM}\right]\left[\mathrm{PF}_{6}\right]$ (from 50 to $150 \mu \mathrm{l})$ as the extraction solvent. As shown in Figure 3, the extraction efficiency increased when the vol-

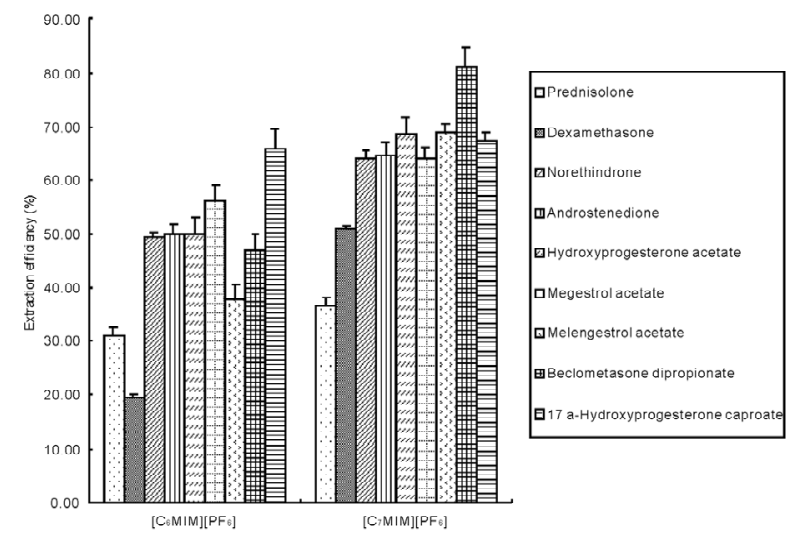

Figure 2. Effect of extraction solvent. ILs volume: $100 \mu \mathrm{l}$; extraction time: $15 \mathrm{~min}$; ultrasonic power: $100 \mathrm{~W}$; salt addition: $0 \mathrm{mg} / \mathrm{ml}$. centrifugation time: $10 \mathrm{~min}(10,000 \mathrm{rpm})$; spiked concentration: $10 \mu \mathrm{g} / \mathrm{ml}$.

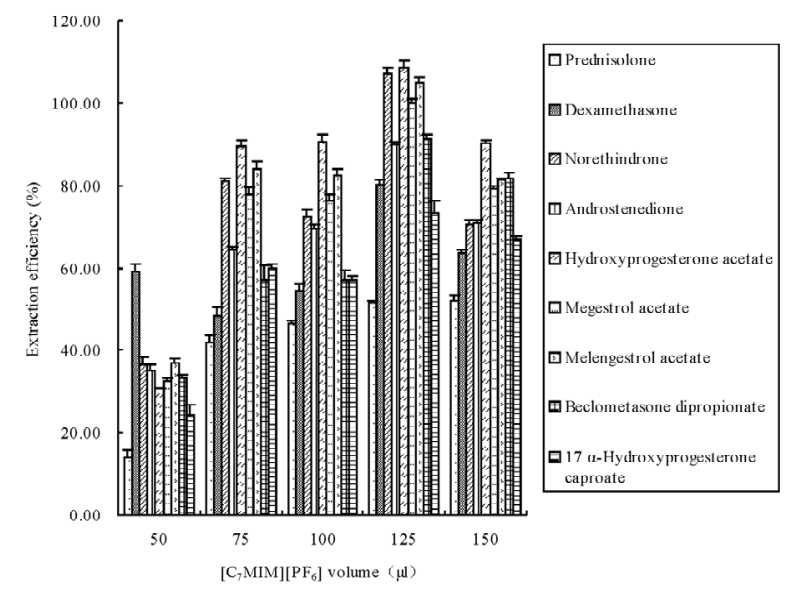

Figure 3. Effect of the volume of $\left[\mathrm{C}_{7} \mathrm{MIM}\right]\left[\mathrm{PF}_{6}\right]$. extraction time: $15 \mathrm{~min}$; ultrasonic power: $100 \mathrm{~W}$; salt addition: 0 $\mathrm{mg} / \mathrm{ml}$. centrifugation time: $10 \mathrm{~min}(10,000 \mathrm{rpm})$; spiked concentration: $10 \mu \mathrm{g} / \mathrm{ml}$. ume of $\left[\mathrm{C}_{7} \mathrm{MIM}\right]\left[\mathrm{PF}_{6}\right]$ increased from 50 to $125 \mu \mathrm{l}$, and decreased obviously above $125 \mu$. The reason could be that the appropriate volume of $\left[\mathrm{C}_{7} \mathrm{MIM}\right]\left[\mathrm{PF}_{6}\right]$ could be dispersed sufficiently into sample solution under ultrasound, but with the volume of $\left[\mathrm{C}_{7} \mathrm{MIM}\right]\left[\mathrm{PF}_{6}\right]$ increased, the hormones could not be transferred into the IL phase sufficiently for its high viscosity and density [12]. Therefore, $125 \mu$ of $\left[\mathrm{C}_{7} \mathrm{MIM}\right]\left[\mathrm{PF}_{6}\right]$ was selected for the further study.

\subsubsection{Effect of Salt Addition}

The influence of salt addition on the performance of ILUSAEME was investigated by adding different amount of $\mathrm{NaCl}(0$ to $9 \%, w / v)$ to solution. The results demonstrated that the salt addition had neglectful effect on the extraction efficiency of analytes. On the other hand, the adequate salt addition is helpful to the formation of IL extraction phase. Consequently, the $9 \% \mathrm{NaCl}$ was used in subsequent experiments.

\subsubsection{Effect of Ultrasonic Power and Time}

In this work, the emulsification of the ionic liquid into sample solution was facilitated by ultrasound radiation. The ultrasonic power can affect the mass transfer rate and the contact area between the sample solution and the ionic liquid extractant. When the ultrasonic power was tested at two different levels: $100 \mathrm{~W}, 500 \mathrm{~W}$, it was obvious that the suitable ultrasonic power should be $100 \mathrm{~W}$.

Additionally, the effect of ultrasonic time on extraction efficiency was evaluated in the range of $5 \mathrm{~min}-25$ min. The results shown in Figure 4 indicated that the extraction efficiency achieved the maximum at the ultrasonic time of $15 \mathrm{~min}$. The main reason may be that adequate ultrasonic time is needed to ensure the equilibrium of extraction. However, prolonging the ultrasonic time induced the descent of extraction efficiency because of the dissolution of IL in sample solution. Consequently, the ultrasonic time of 15 min was enough.

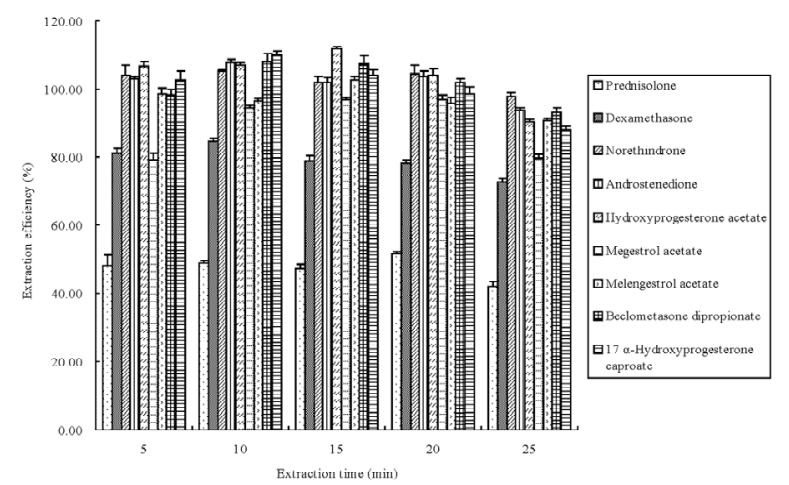

Figure 4. Effect of extraction time. $\left[\mathrm{C}_{7} \mathrm{MIM}\right]\left[\mathrm{PF}_{6}\right]$ volume: $125 \mu \mathrm{l}$; salt addition: $9 \%(\mathrm{~m} / \mathrm{v})$; ultrasonic power: $100 \mathrm{~W}$; centrifugation time: $10 \mathrm{~min}(10,000 \mathrm{rpm})$; spiked concentration: $10 \mu \mathrm{g} / \mathrm{ml}$. 


\subsubsection{Effect of Centrifugation Time}

The centrifugation plays an important role on the sedimentation of IL phase. The effect of centrifugation time ranging from 9 to 21 min was tested. As observed in Figure 5, the extraction efficiency of the most analytes increased with the increase of the centrifugation time from 9 to $12 \mathrm{~min}$. When the centrifugation time was longer than $12 \mathrm{~min}$, the extraction efficiency of dexamethasone, hydroxyprogesterone acetate and beclometasone dipropionate decreased and no significant change was observed for others. Therefore, $12 \mathrm{~min}$ was chosen as the centrifugation time.

\subsection{Evaluation of the method}

The chromatogram of a spiked sample obtained by ILUSAEME under the optimum conditions was shown in Figure 6. Under the optimum conditions, linear range, limits of detection (LODs), recovery and precision were determined and shown in Tables $\mathbf{1}$ and 2. As can be seen, good linearities were observed for all analytes with the coefficient of correlation $\left(r^{2}\right)$ ranging from 0.9980 to 0.9994. The LODs were calculated at a signal-to-noise $(\mathrm{S} / \mathrm{N})$ ratio of 3 . The mean recoveries were $62.30 \%$ $108.84 \%$ and the RSDs were $0.26 \%-4.69 \%$. The intraday and interday precisions varied from $0.10 \%$ to $2.51 \%$ and from $0.33 \%$ to $3.30 \%$, respectively. The results demonstrated that the method is potential for the detection of hormones fortified in cosmetics.

\section{Conclusion}

In this study, a simple, cheap and green IL-USAEME combined with HPLC method was developed and successfully applied to simultaneously determine three glucocorticoids, one androgen and five progestogens in cosmetics, in which using ultrasound radiation to facilitate

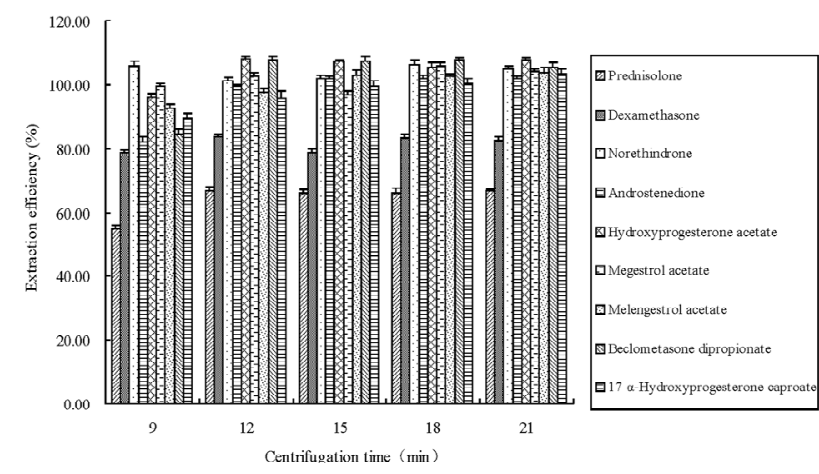

Figure 5. Effect of centrifugation time. $\left[\mathrm{C}_{7} \mathrm{MIM}\right]\left[\mathrm{PF}_{6}\right]$ volume: $125 \mu \mathrm{l}$; salt addition: $9 \%(\mathrm{~m} / \mathrm{v})$; ultrasonic power: 100 $\mathrm{W}$; extraction time: $15 \mathrm{~min}$; spiked concentration: $10 \mu \mathrm{g} / \mathrm{ml}$.

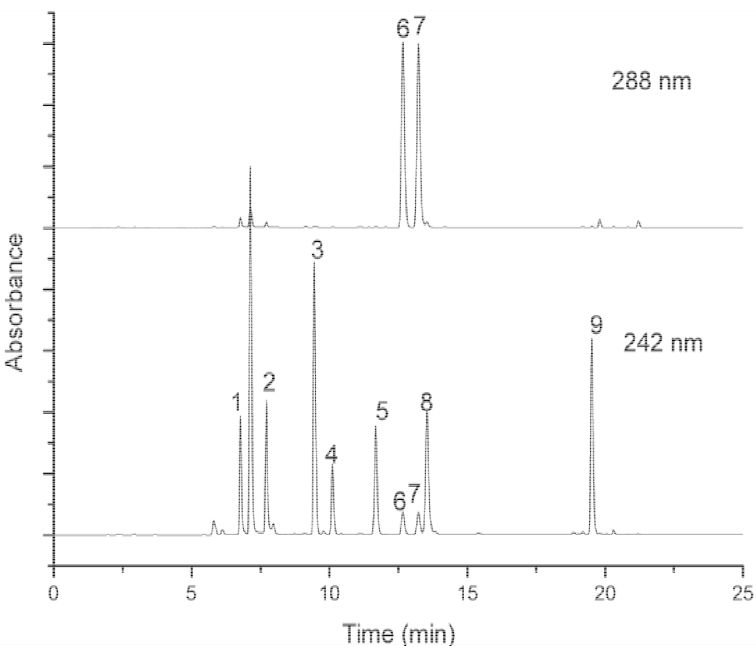

Figure 6. Chromatogram of spiked sample obtained at wavelength 242 and $288 \mathrm{~nm}$. (1) prednisolone, (2) dexamethasone, (3) norethindrone, (4) androstenedione, (5) hydroxyprogesterone acetate, (6) megestrol acetate, (7) melengestrol acetate, (8) beclometasone dipropionate, (9) 17 a-hydroxyprogesterone caproate.

Table 1. Method calibration data and recoveries of analytes.

\begin{tabular}{|c|c|c|c|c|c|}
\hline \multirow{2}{*}{ Analyte } & \multirow{2}{*}{ Linear range $(\mu \mathrm{g} / \mathrm{ml})$} & \multirow{2}{*}{ Correlation coefficient $\left(r^{2}\right)$} & \multirow{2}{*}{ LOD $(\mu \mathrm{g} / \mathrm{g})$} & \multicolumn{2}{|c|}{ Mean recovery $(\%)(n=3)$} \\
\hline & & & & $1(\mu \mathrm{g} / \mathrm{ml})$ & $10(\mu \mathrm{g} / \mathrm{ml})$ \\
\hline Prednisolone & $0.50-100.00$ & 0.9994 & 0.15 & $62.30 \pm 1.63$ & $66.45 \pm 1.23$ \\
\hline Dexamethasone & $0.60-120.00$ & 0.9991 & 0.40 & $98.34 \pm 0.26$ & $95.11 \pm 0.76$ \\
\hline Norethindrone & $0.20-100.00$ & 0.9990 & 0.10 & $99.86 \pm 0.24$ & $92.12 \pm 3.60$ \\
\hline Androstenedione & $0.10-50.00$ & 0.9992 & 0.20 & $101.75 \pm 1.69$ & $88.11 \pm 2.87$ \\
\hline Hydroxyprogesterone acetate & $0.60-120.00$ & 0.9980 & 0.40 & $98.07 \pm 3.50$ & $97.16 \pm 3.38$ \\
\hline Megestrol acetate & $0.10-50.00$ & 0.9991 & 0.05 & $105.09 \pm 2.82$ & $85.97 \pm 2.02$ \\
\hline Melengestrol acetate & $0.10-50.00$ & 0.9991 & 0.10 & $100.21 \pm 2.61$ & $92.49 \pm 1.73$ \\
\hline Beclometasone dipropionate & $1.00-200.00$ & 0.9991 & 0.85 & $108.84 \pm 3.42$ & $106.86 \pm 4.69$ \\
\hline $17 \alpha$-Hydroxyprogesterone caproate & $0.30-150.00$ & 0.9992 & 0.25 & $95.26 \pm 3.91$ & $98.19 \pm 4.38$ \\
\hline
\end{tabular}


Table 2. Intraday and interday precision.

\begin{tabular}{|c|c|c|c|c|c|c|}
\hline \multirow{2}{*}{ Analyte } & \multicolumn{3}{|c|}{ Intraday $^{\mathrm{a}}(\mathrm{RSD} \%)$} & \multicolumn{3}{|c|}{ Interday $^{\mathrm{b}}(\mathrm{RSD} \%)$} \\
\hline & $1(\mu \mathrm{g} / \mathrm{ml})$ & $5(\mu \mathrm{g} / \mathrm{ml})$ & $25(\mu \mathrm{g} / \mathrm{ml})$ & $1(\mu \mathrm{g} / \mathrm{ml})$ & $5(\mu \mathrm{g} / \mathrm{ml})$ & $25(\mu \mathrm{g} / \mathrm{ml})$ \\
\hline Prednisolone & 1.91 & 0.45 & 0.57 & 1.54 & 0.94 & 0.68 \\
\hline Dexamethasone & 1.82 & 0.88 & 0.61 & 2.01 & 0.40 & 0.70 \\
\hline Norethindrone & 1.74 & 0.99 & 0.38 & 0.68 & 0.36 & 0.57 \\
\hline Androstenedione & 1.33 & 0.89 & 0.45 & 0.87 & 0.96 & 0.45 \\
\hline Hydroxyprogesterone acetate & 0.26 & 0.47 & 0.08 & 1.52 & 0.58 & 0.44 \\
\hline Megestrol acetate & 0.85 & 0.47 & 0.10 & 1.65 & 0.73 & 0.50 \\
\hline Melengestrol acetate & 1.05 & 0.09 & 0.64 & 1.97 & 0.87 & 0.42 \\
\hline Beclometasone dipropionate & 0.60 & 0.52 & 0.34 & 3.30 & 0.69 & 0.57 \\
\hline $17 \alpha$-Hydroxyprogesterone caproate & 2.51 & 1.01 & 0.88 & 0.90 & 0.33 & 0.90 \\
\hline
\end{tabular}

${ }^{\mathrm{a}}$ The intraday precision was gained by analyzing a sample three times in one day. ${ }^{\mathrm{b}}$ The interday precision was received by analyzing a sample once a day over three consecutive day.

the emulsification of a microvolume of ionic liquid instead of organic solvent into the sample solution. The experimental conditions for the extraction of these analytes have been investigated. Under the optimized conditions, satisfactory extraction efficiency of the analytes was obtained.

\section{Acknowledgements}

We gratefully acknowledge the financial support from socially useful projects under the Zhejiang Province Science and Technology Department (2010C33074) and the project supported by the Zhejiang University of Technology Foundation (20070167).

\section{REFERENCES}

[1] Y. Liu, X. L. Zhang, Y. Z. Ouyang, Z. HU, L. Ma, et al., "Trace Detection of Hormones and Sulfonamides in Viscous Cosmetic Products by Neutral Desorption Extractive Electrospray Ionization Tandemmass Spectrometry," Journal of Mass Spectrometry, Vol. 46, No. 8, 2011, pp. 794803. doi:10.1002/jms. 1944

[2] M. Plotan, C. Frizzell, V. Robinson, C. T. Elliott and L. Connolly, "Endocrine Disruptor Activity in Bottled Mineral and Flavored Water," Food Chemistry, Vol. 136, No. 3-4, 2013, pp. 1590-1596. doi:10.1016/j.foodchem.2012.01.115

[3] C. Kai, C. T. Elliott, D. H. Phillips, M.-L. Scippo, M. Muller, et al., "Treatment of Estrogens and Androgens in Dairy Wastewater by a Constructed Wetland System," Water Research, Vol. 46, No. 7, 2012, pp. 2333-2343. doi:10.1016/j.watres.2012.01.056

[4] C. S. Tamvakopoulos, J. M. Neugebauer, M. Donnelly and P. R. Griffin, "Analysis of Betamethasone in Rat Plasma Using Automated Solid-Phase Extraction Coupled with Liquid Chromatography-Tandem Mass Spectrome- try. Determination of Plasma Concentrations in Rat Following Oral and Intravenous Administration," Journal of Chromatography B, Vol. 776, No. 2, 2002, pp. 161-168. doi:10.1016/S1570-0232(02)00271-4

[5] Z. G. Zhang, B. Shi, G. F. Wang, L. Y. Lin and Y. Zhou, "Determination of Medroxyprogesterone Acetate in Aquatic Product by Liquid Chromatography with Tandem Mass Spectrometric Detection," Journal of Chinese Mass Spectrometry Society, Vol. 27, No. 1, 2006, pp. 36-39.

[6] X. J. Cao, X. M. Ye, Y. B. Lu, Y. Yu and W. M. Mo, "Ionic Liquid-Based Ultrasonic-Assisted Extraction of Piperine from White Pepper," Analytica Chimica Acta, Vol. 640, No. 1-2, 2009, pp. 47-51. doi:10.1016/j.aca.2009.03.029

[7] X. J. Cao, J. F. Qiao, L. P. Wang, X. M. Ye, L. B. Zheng, et al., "Screening of Glycoside Isomers in P. Scrophulariiflora Using Ionic Liquid-Based Ultrasonic-Assisted Extraction and Ultra-performance Liquid Chromatography/ electrospray Ionization Quadrupole Time-of-Flight Tandem Mass Spectrometry," Rapid Communications in Mass Spectrometry, Vol. 26, No. 7, 2012, pp. 740-748. doi: $10.1002 / \mathrm{rcm} .6158$

[8] R. Zhang, N. Li, C. L. Wang, Y. P. Bai, R. B. Ren, et al., "Ionic Liquid Foam Floatation Coupled with Solid Phase Extraction for Separation and Determination of Hormones by High-Performance Liquid Chromatography," Analytica Chimica Acta, Vol. 704, No. 1-2, 2011, pp. 98-109. doi:10.1016/j.aca.2011.08.016

[9] M. Q. Kang, S. Sun, N. Li, D. H. Zhang, M. Y. Chen, et al., "Extraction and Determination of Hormones in Cosmetics by Homogeneous Ionic Liquid Microextraction High-Performance Liquid Chromatography," Journal of Separation Science, Vol. 35, No. 16, 2012, pp. 2032-2039. doi: $10.1002 /$ jssc. 201200206

[10] L. Fischer, T. Falta, G. Koellensperger, A. Stojanovic, D. Kogelnig, et al., "Ionic Liquids for Extraction of Metals and Metal Containing Compounds from Communal and 
Industrial Waste Water," Water Research, Vol. 45, No. 15, 2011, pp. 4601-4614.

doi:10.1016/j.watres.2011.06.011

[11] D. D. Ge and H. K. Lee, "A New 1-Hexyl-3-Methylimidazolium tris (Pentafluoroethyl)Trifluorophosphate Ionic Liquid Based Ultrasound-Assisted Emulsification Microextraction for the Determination of Organic Ultraviolet Filters in Environmental Water Samples," Journal of Chromatography A, Vol. 1251, 2012, pp. 27-32. doi:10.1016/j.chroma.2012.06.048

[12] P. Liang, F. Wang, Q. Wan, "Ionic Liquid-Based Ultrasound-Assisted Emulsification Microextraction Coupled with High Performance Liquid Chromatography for the Determination of Four Fungicides in Environmental Water Samples," Talanta, Vol. 105, 2013, pp. 57-62. doi:10.1016/j.talanta.2012.11.065

[13] N. M. Najafi, H. Tavakoli, Y. Abdollahzadeh and R.
Alizadeh, "Comparison of Ultrasound-Assisted Emulsification and Dispersive Liquid-Liquid Microextraction Methods for the Speciation of Inorganic Selenium in Environmental Water Samples Using Low Density Extraction Solvents," Analytica Chimica Acta, Vol. 714, No. 7, 2012, pp. 82-88. doi:10.1016/j.aca.2011.11.063

[14] V. Herrera-Herrera, M. Asensio-Ramos, J. HernándezBorges and M. Á. Rodríguez-Delgado, "Dispersive Liquid Liquid Microextraction for Determination of Organic Analytes," Trends in Analytical Chemistry, Vol. 29, No. 7, 2010, pp. 728-751.doi:10.1016/j.trac.2010.03.016

[15] C. F. Poole and S. K. Poole, "Extraction of Organic Compounds with Room Temperature Ionic Liquids," Journal of Chromatography A, Vol. 1217, No. 16, 2010, pp. 22682286. doi:10.1016/j.chroma.2009.09.011 